\title{
Cervical Cancer and HPV Vaccine in Nepal: Issues and Challenges
}

\author{
Dangal G \\ Department of Obs/Gyn, Kathmandu Model Hospitals, Exhibition Road, Kathmandu
}

Cervical cancer is a major public health problem of developing countries like Nepal. It is the second most common cancer and a leading killer among women worldwide and is the principal cancer of women in most developing countries, where 80 percent of cases occur ${ }^{1}$. The primary cause of carcinoma cervix is Human Papilloma Virus (HPV) infection, the most common sexually transmitted infection worldwide.

It is also a major cause of morbidity and mortality in Nepal, as in other countries within South Asia and developing countries worldwide, where some suggest it causing as high as $34 \%$ of all cancers in women ${ }^{2}$. A Pap test is the best way to detect cell changes that may be an early sign of precancer of the cervix. There are now other screening tools available e.g. visual inspection of cervix with acetic acid for resource poor settings, and HPV DNA test for those who can afford.

The use of HPV prophylactic vaccine among young adolescents (age of 9-13), who have not been previously exposed to the infection, as primary prevention holds most promise for the prevention of cervical cancer ${ }^{3}$. But, the unfortunate reality of this disease is that in spite of its being completely preventable, we in Nepal, unlike in the west, have not yet been able to prevent $\mathrm{it}^{4}$.

Vaccinations are one of the most successful public health approaches to preventing and controlling many infectious diseases. New vaccines (Gardasil and Cervirax), a great breakthrough of the $21^{\text {st }}$ century, are available which protect against the major types of HPV that cause the most cases of cervical cancer. They are highly effective in preventing the HPV infection and are already available in the developed world. It costs US $\$ 360$ for a set of three doses. The second and third doses should be given at two and six months after the first dose. As the vaccine does not protect against all types of HPV and will not prevent all cases of cervical cancer or genital warts, women who are vaccinated should still have regular Pap tests. The vaccine which is very safe to use, is a preventive tool and is not a substitute for cancer screening.

Though the vaccine will be most effective if received before the onset of sexual activity (9-13 years of age), vaccination can be offered to those who are already sexually active as well, regardless of a previous history of HPV infection or an abnormal Pap test.

An effective HPV vaccine, and one that is accepted, could have enormous public health benefits for both men and women by decreasing the morbidity and mortality associated with HPV related cancer. The mass administration of an HPV vaccine provides great potential for improving the health of millions of women, as well as men and it has the potential to reduce cervical cancer deaths around the world by as much as two-thirds, if all women were to take vaccine and if protection turns out to be long term. The approval of the vaccine against cancer-causing HPV strains is significant in the public health world, but more so in developing countries like Nepal which lack the health care resources for routine cervical cancer screening, therefore saving millions of lives.

The society generally perceives that cervical cancer is the problem of women, and believes there is minimum or no role of men in transmitting the virus to women. However, the contrary is true and to prevent infection from HPV to females, males should be vaccinated as well. Moreover, there are disputes over whom to vaccinate and whether it should become national program run by government or paid by adolescent's parents.

Even though the vaccine provides protection from developing HPV associated cervical cancer, many adolescents are reluctant and their parents are not

\author{
CORRESPONDENCE \\ Dr. Ganesh Dangal, MD, FICS \\ Department of Obstetrics and Gynaecology \\ Kathmandu Model Hospital \\ GPO Box 12887, Kathmandu, Nepal \\ Phone: 00977-1-5250802 \\ Cell: 00977-9851055036 \\ E-mail: gareshma@hotmail.com
}


endorsing the vaccination due to the barriers such as parental acceptability, fear of promiscuity in the teenagers, myths and high cost. There is still uncertainty about whether the vaccine can last its immunogenicity for long or just a few years. The protective effects of the vaccine are proven to last a minimum of 5 years after the initial vaccination. Other unresolved issues include long-term protection, cross-protection against HPV types not included in the vaccine and whether booster doses will be needed. Another issue of concern is the high cost associated with the vaccination; with the present cost it is practically impossible to implement mass vaccination in Nepal. Another concern is about the argument that vaccination could "promote promiscuity" but there is no evidence suggesting a connection between a decrease in HPV and an increase in sexual activity. Lack of awareness, public demand and political will, lack of coordination between cancer control, sexual and reproductive health and vaccine delivery services are additional challenges.

The single-most barrier to the introduction of the vaccine for the adolescents in Nepal is the unaffordable high price. From a public health perspective, the first priority in resource-poor settings would be to vaccinate young adolescent girls by school-based or community based vaccination programs.
And there are rays of hope, the noble work of vaccinating our school girls has been initiated in Nepal and GAVI's announcement of providing the vaccines to developing countries in highly subsidized price (US $\$ 5$ per dose) is also a positive step.

This is now high time that a serious consideration for widespread use of HPV vaccine in this country needs topmost priority. This will only be possible through public awareness, cultural acceptability, political will, policy formulation and public support.

\section{REFERENCES}

1. Ferlay J, Bray F, Pisani P, Parkin DM. Globocan 2002: Cancer incidence, mortality and prevalence worldwide. IARC Cancer Base no. 5, version 2.0, Lyon, France: IARC Press;2004.

2. The International Network for Cancer Treatment and Research Perspectives in cervical cancer prevention in India. [Online] [cited 2009 Sep 05]. Available from; URL: http://www.inctr.org/ publications/2003_v03_n03_w02.shtml

3. Prasai S. Human papilloma virus vaccination: Should it be mandatory? J Nepal Med Assoc.2008;47(171):167-71.

4. Singh $M$. The major breakthrough of the 21 st century- HPV vaccine. N J Obstet Gynaecol.2007 Nov-Dec;2(2):1-2. 